\title{
Inquilinus limosus
}

National Cancer Institute

\section{Source}

National Cancer Institute. Inquilinus limosus. NCI Thesaurus. Code C86445.

A species of Gram negative, rod shaped bacteria assigned to the phylum Proteobacteria.

This species is oxidase and beta galactosidase positive and nonfermentative. I. limosus has been isolated from the respiratory tract of cystic fibrosus patients and is considered a multidrug resistant pathogen. 